\title{
Therapeutic Approach to Patients Complaining of High Blood Pressure in a Cardiological Emergency Room
}

\author{
Miguel Gus, André G. Andrighetto,Vanessa R. Balle, Marco B. Pilla \\ Porto Alegre, RS - Brazil
}

\begin{abstract}
Objective - To evaluate the management of patients complaining of high blood pressure $(B P)$ in a cardiological emergency room.
\end{abstract}

Methods - Patients referred to the cardiological emergency room with the main complaint of high blood pressure were consecutively selected. The prescriptions and the choice of antihypertensive drugs were assessed. The classification of these patients as hypertensive emergencies or pseudoemergencies, according to the physician who provided initial care, was recorded.

Results - From a total of 858 patients presenting to the emergency room, 80 (9.3\%) complained of high BP, and 61 (76.3\%) received antihypertensive drugs. Sublingual nifedipine was the most commonly used drug (59\%). One patient received intravenous medication, one patient was hospitalized and 6 patients (7.5\%) were classified as hypertensive emergencies or pseudoemergencies.

Conclusion - High BP could seldom be classified as a hypertensive emergency or pseudoemergency, even though it was a frequent complaint (9.3\% of visits). Currently, the therapeutic approach is not recommended, even in specialized clinics.

Keywords: hypertensive emergency and pseudoemergency, nifedipine
Instituto de Cardiologia do Rio Grande do Sul/Fundação Universitária de Cardiologia - Porto Alegre

Mailing Address: Miguel Gus - Instituto de Cardiologia do RS - Av. Princesa Isabel, 395 - 90620-001 - Porto Alegre, RS - Brazil
The management of patients with acutely increased arterial blood pressure depends on the classification of this condition into hypertensive emergency or pseudoemergency ${ }^{1}$.

Hypertensive emergencies are conditions that require immediate lowering of the blood pressure (BP) (not necessarily to normal levels) to prevent or limit the damage to target organs. At first, patients are treated with parenteral drugs ${ }^{1}$. On the other hand, in hypertensive pseudoemergencies, the increases in BP are not associated with immediate and severe consequences, allowing the reduction of BP in a period of up to 24 hours using oral drugs ${ }^{2}$.

Nifedipine has been largely employed in emergency departments for the management of patients with acutely increased BP. Early reports indicated that nifedipine was an effective, easily administered, cost-effective and apparently safe $\operatorname{drug}^{3}$. However, recent evidence suggests that its indiscriminate use in hypertensive emergencies and pseudoemergencies may lead to serious side effects, such as cerebrovascular ischemia, severe hypotension, acute myocardial infarction (AMI), conduction disturbances, fetal distress and increased mortality ${ }^{4}$.

In spite of all these disadvantages, a series of emergency departments have adopted "cosmetic therapy of BP" as a routine practice. In this study, the authors evaluate the management of patients who presented to a cardiological emergency department with the main complaint of high BP.

\section{Methods}

During a six month period (November/96 to April/97), patients who arrived at a cardiological emergency department complaining of acutely increased BP (major complaint according to the patient's medical record $=$ high BP) were selected. After obtaining an informed consent, the patients selected had their BP measured and received a standard questionnaire, which included questions about the symptoms and duration of hypertension, previous use of antihypertensive drugs and comorbidities. Therapeutic 
approaches and the classification as hypertensive emergency or pseudoemergency were registered. The diagnoses listed in the medical records, as well as the management of the condition, were established by the physicians in the emergency department, who provided the initial care according to the routine practice of the clinic. These physicians were not aware of the study's objective.

Data were randomly collected during all working hours in the emergency department. They were then stored in an Access 2.0 software database and analyzed by the SPSS 5.01 software. The data are presented in a descriptive form as means, standard deviation and percentage.

\section{Results}

Of 858 patients evaluated in the cardiological emergency department during the study, $80(9.3 \%)$ said that high $\mathrm{BP}$ was their main symptom. The mean age was $52 \pm 14.3$ years. There were 57 (71.2\%) females and 23 (28.8\%) males. $74 \%$ of the patients were white. The symptoms more often associated with high BP were headache $(36.3 \%)$, dizziness $(28.8 \%)$ and chest pain (22.5\%). Mean systolic and diastolic blood pressures were $182 \pm 36.6 \mathrm{mmHg}$ and $110 \pm 22.9 \mathrm{mmHg}$, respectively.

Complaints of high BP were treated in $76.3 \%$ of the cases. Sublingual nifedipine was the most commonly used $\operatorname{drug}(59 \%)$ (fig. 1). One patient received intravenous medication (nitroglycerin), one patient was hospitalized due to nonsustained ventricular tachycardia and conges-tive heart failure complicated with acute pulmonary edema. This patient also suffered from hypertensive nephropathy (creatinine level $=2.54$ ). Six patients $(7.5 \%)$ were classified as hypertensive pseudoemergencies or emergencies by the physicians of the department.

\section{Discussion}

In a previous study ${ }^{5}$, the authors noted that high BP is a frequent complaint in emergency departments, being the fourth most prevalent complaint and corresponding to $9.3 \%$ of all visits to the department.

Recent evidence suggests that high BP alone, without symptoms, rarely requires specific emergency therapy ${ }^{1}$. However, in our sample, $76.3 \%$ of our patients received antihypertensive drugs, most of them without a precise indication, as only $7.5 \%$ were classified by the attending physician as a hypertensive emergency or pseudoemergency.

Since the middle 80s', nifedipine has been advocated as a safe, effective and easily administered drug for the management of hypertensive crisis. The choice of a less expensive drug, that does not require the intravenous administration in an intensive care unit, made nifedipine more convenient than sodium nitroprusside, without significantly increasing morbidity and mortality ${ }^{6}$. Later, it was demonstrated that, although nifedipine is a good option for the management of hypertensive crisis, the sublingual route was not optimal. Its therapeutic effects were reported to be the result of ingestion rather than sublingual absorption ${ }^{7}$.

Similarly, the safety of nifedipine in the management of hypertensive crisis was questioned ${ }^{4}$. Myocardial and cere-

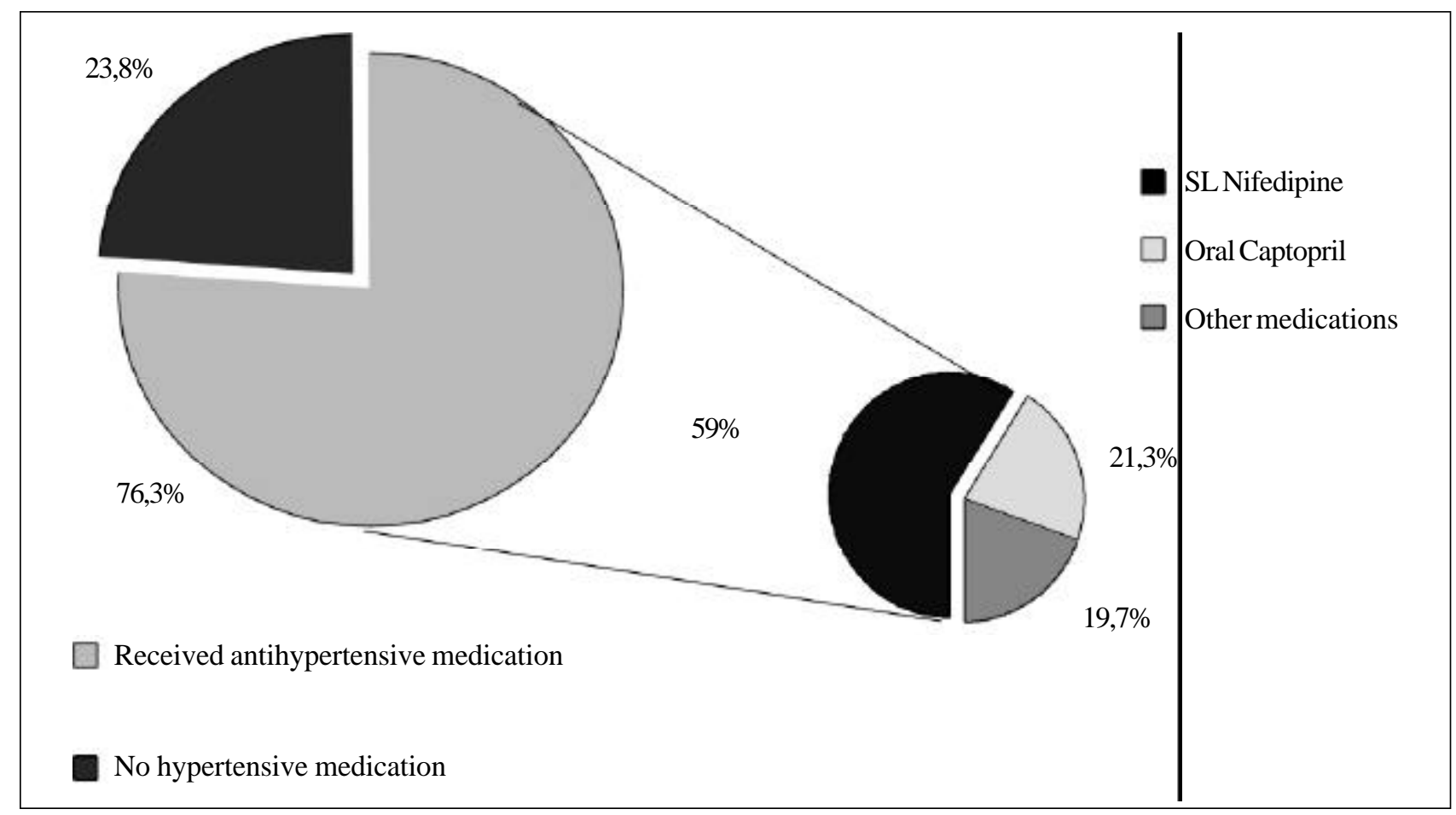

Fig. 1 - Therapy directed to patients complaining of high BP. 
bral ischemia as a result of severe hypotension induced by nifedipine was reported. It is speculated that these adverse events would occur as a result of three different mechanisms: 1) unpredictable lowering of BP per se; 2) systemic vasodilation, which would shift the blood to the peripheral circulation; and 3) reflex cardioacceleration and excessive release of catecholamines, increasing heart contractility and work. This may worsen preexistent myocardial ischemia ${ }^{8}$.

In fact, evidence shows that increasing doses of short-acting nifedipine are related to an increased risk of mortality. Thus, they must be avoided in AMI survivors or in patients with stable and unstable angina ${ }^{8,9}$.

These reasons, together with the absence of more consistent evaluations of the efficacy of short-acting calcium antagonists in hypertensive emergencies and pseudoemergencies, led American regulatory agencies ${ }^{1}$ to consider the use of nifedipine unacceptable in these conditions, advocating that this drug should be abandoned ${ }^{4}$.

In spite of evidence showing that "cosmetic therapy" of BP does not bring any benefit, this practice has continued in most emergency departments. The present study demonstrates that most patients presenting to a specialized emergency department complaining of high BP (which alone seems a mistake) receive a therapy that is considered inadequate, useless and, to a certain degree, dangerous. In addition, this therapy may be considered expensive if one takes into account the number of patients presenting to these departments with this complaint (10\% of all visits). In view of this evidence, continuous information to the general public and to health professionals working in this area is deemed necessary.

\section{References}

1. The sixth report of the Joint National Committee on Prevention, Detection, Evaluation, and Treatment of High Blood Pressure (JNC VI). Arch Intern Med 1997; 157: 2413-45.

2. Fuchs FD, Lubianca Neto JF, Neves JM - Urgência e emergência hipertensivas. Arq Bras Cardiol 1991; 56: 243-6.

3. Ellrodt AG, Ault MJ, Riedinger MS, Murata GH - Efficacy and safety of sublingual nifedipine in hypertensive emergencies. Am J Med 1985; 79(suppl 4A): 19-25.

4. Grossman E, Messerli FH, Grodzicki T, Kowey P - Should a moratorium be placed on sublingual nifedipine capsules given for hypertensive emergencies and pseudoemergencies? JAMA 1996; 276: 1328-31.

5. Andrighetto AG, Pilla MB, Kronbauer AL, et al - Prevalência de consultas em emergência cardiológica por pressão arterial elevada. Anais do VIII Congresso de Cardiologia da Sociedade Brasileira de Cardiologia - Rio Grande do Sul, 1997: 89

6. Franklin C, Nightingale S, Mandani B - A randomized comparison of nifedipine and sodium nitroprusside in severe hypertension. Chest 1986; 90: 500-3.

7. Van Harten J, Burggraaf K, Danhof M, Van Brummelen P, Breimer D - Negligible sublingual absorption of nifedipine. Lancet 1987; 2: 1363-5.

8. Furberg CD, Psaty BM, Meyer JV - Nifedipine dose-related increase in mortality in patients with coronary heart disease. Circulation 1995; 92: 1326-31.

9. Psaty BM, Heckbert SR, Koepsell TD, et al - The risk of myocardial infarction associated with antihypertensive drug therapies. JAMA 1995; 274: 620-5. 